\title{
A STUDY ON SUTURAL MORPHOLOGY OF THE PTERION IN ADULT DRY SKULL IN SOUTH INDIAN ETHNIC GROUP
}

\section{Qudsia Sultana *1, Mohammad Hafeezulla Shariff ${ }^{2}$, Venkatesh Kamatth ${ }^{3}$, Ramakrishna Avadhani ${ }^{4}$.}

\footnotetext{
${ }^{{ }^{1}}$ Assistant Professor, Department of Anatomy, Yenepoya Medical College, Mangalore, Karnataka, India.
}

${ }^{2}$ Associate Professor, Department of Pathology, Yenepoya Medical College, Mangalore, Karnataka, India.

${ }^{3}$ Associate Professor, Department of Anatomy, Yenepoya Medical College, Mangalore, Karnataka, India.

${ }^{4}$ Professor, Department of Anatomy, Yenepoya Medical College, Mangalore, Karnataka, India.

\section{ABSTRACT}

Introduction: The latest advances in the field of pterional keyhole surgeries make it imperative for a neurosurgeon to understand the sutural morphology of pterion prior to the surgery.

Materials and Methods: The sutural morphology of the pterion was studied bilaterally in 98adult skulls (62 male and 36 female) of south Indian ethnic group. The pterion was classified into four types namely sphenoparietal, frontotemporal, stellate and epipteric and the frequency of each type was observed bilaterally and in either sex and recorded.

Results: Sphenoparietal was observed to be the commonest type of the pterion comprising $81.61 \%$, followed by epipteric and frontotemporal varieties comprising 7.63 and $6.63 \%$ respectively and stellate was observed to be the least common variety with $3.55 \%$.

Conclusion: The pterion is an important neurosurgical landmark due to the presence of vital structures beneath it such as the insula, middle meningeal artery, Broca's area, optic nerve and the circle of Willis. It provides lateral access to these structures and enables surgical treatment of vascular aneurysms of circle of Willis, tumours and optic meningiomas. The novel advances in the field of pterional keyhole surgeries increases its significance and a neurosurgeon must essentially understand its sutural morphology prior to surgery.

KEY WORDS: Neurosurgical Implications, Pterion, Pterionic Approach, Sutural Morphology.

Address for Correspondence: Dr.Qudusia Sultana, Assistant Professor, Department of Anatomy, Yenepoya Medical College, Mangalore, India- 575018. Mobile: +91-7899114567.

Mobile: +91- 7899114567 E-Mail: qudsia.shariff@yahoo.co.in

\section{Access this Article online}

\section{Quick Response code}

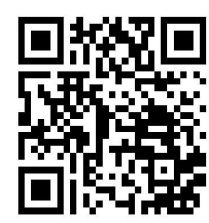

DOI: $10.16965 /$ ijar.2017.260

Web site: International Journal of Anatomy and Research

ISSN 2321-4287

www.ijmhr.org/ijar.htm

Received: 05 May 2017

Peer Review: 05 May 2017

Revised: 18 May 2017
Accepted: 18 Jun 2017

Published (0): 31 Jul 2017

Published (P): 31 Jul 2017

\section{INTRODUCTION}

Pterion is an $\mathrm{H}$ shaped suture on the lateral aspect of the skull marking the confluence of the frontal bone, the parietal bone, the greater wing of sphenoid and the squamous part of temporal bone representing the neonatal anterolateral fontanelle [1]. It was Murphy who first classified pterion into four types. The four types 
include sphenoparietal, frontotemporal, stellate and epipteric. The sphenoparietal type involves fusion of greater wing of sphenoid and parietal bone, the Frontotemporal type involves fusion of frontal and temporal bones, the stellate type involves fusion of all the four bones which meet at a point and in the Epipteric type a sutural bone is found in the pterion [2]. The position of pterion is marked approximately by a point 3 to $4 \mathrm{~cm}$ above the midpoint of zygomatic arch and 3 to $4 \mathrm{~cm}$ behind frontozygomatic suture [3]. The pterion is a point of immense neurosurgical significance as it provides surgical access to several vital structures such as middle meningeal artery, circle of Willis, insula and Broca's motor speech area in procedures such as trephination for extradural haematoma, treatment of circle of Willis aneurysms and for surgeries involving the insula and the Broca's area [4]. The anterolateral fontanelle can be used for age estimation as it closes 3 months after birth. The position of the pterion also exhibits sexual dimorphism [5]. The Pterional keyhole approach for the treatment of circle of Willis aneurysms is described by several authors $[6,7]$. The present study analyses the sutural morphology of pterion in south Indian ethnic group. It is essential to understand the sutural morphology of the pterion prior to drilling of the burr hole. The point of surgical drilling has to be precise as an anterior drilling will result in penetration of the orbit. A posterior drilling will move away from the surgical field resulting in ineffective access for instrumentation.

\section{MATERIALS AND METHODS}

The study was conducted in the Department of Anatomy in Yenepoya Medical College, Mangalore. The study involved 98 skulls (62 male and 36 female) of south Indian ethnic group. The frequency of each type of pterion was observed bilaterally in all the skulls and recorded. The frequency of each type of pterion in either sex was also observed and recorded.

\section{RESULTS}

All four types of pterion were observed and the results were tabulated and compared with the results of previous studies. Sphenoparietal was observed to be the commonest type of pterion comprising $81.61 \%$, followed by epipteric and frontotemporal varieties comprising $7.63 \%$ and $6.63 \%$ respectively and stellate was observed to be the least common variety with $3.55 \%$. The Sphenoparietal type is shown in figure 1, the frontotemporal type in figure 2, the stellate type in figure 3 and the Epipteric type in figure 4. The frequency of each type of pterion on each side of the skull is shown in table 1 . The frequency of each type of pterion in males and females is shown in table 2.

Table 1: Depicts the frequency of each type of pterion on each side of the skull.

\begin{tabular}{|c|c|c|c|c|}
\hline Side & Sphenoparietal & Frontotemporal & Stellate & Epipteric \\
\hline Right (\%) & 79.59 & 8.16 & 1.52 & 10.18 \\
\hline Left(\%) & 81.63 & 7.14 & 2.54 & 8.16 \\
\hline
\end{tabular}

Table 2: Depicts the frequency of each type of pterion in males and females.

\begin{tabular}{|c|c|c|c|c|}
\hline Sex & Sphenoparietal & Frontotemporal & Stellate & Epipteric \\
\hline Male(\%) & 83.46 & 8.87 & 0 & 6.94 \\
\hline Female(\%) & 78.77 & 3.77 & \multicolumn{2}{|c|}{7.94} \\
\hline Total (\%) & 81.61 & 6.63 & 3.55 & 7.63 \\
\hline
\end{tabular}

Fig. 1: Depicts the sphenoparietal type.Fig. 2 depicts the frontotemporal type.

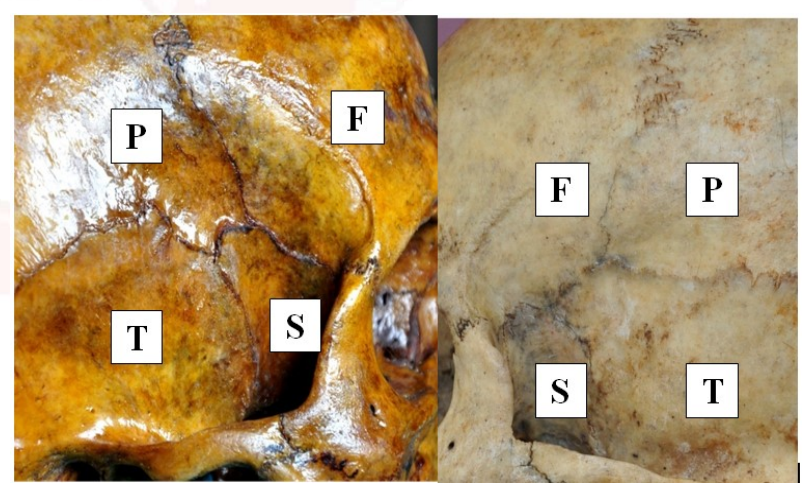

Fig. 2: Represents the stellate type.Fig. 4 depicts the epipteric type.

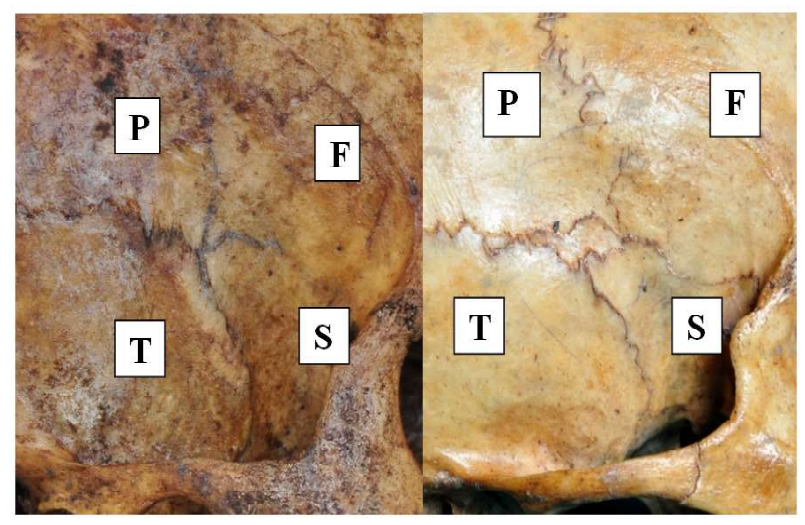

In the above figures " $\mathrm{F}$ " depicts the frontal bone, " $T$ " depicts the squamous part of temporal bone, " $S$ " depicts the greater wing of sphenoid bone and "P" depicts the parietal bone. 


\section{DISCUSSION}

The sutural morphology of pterion has been studied in diverse ethnic groups by several authors as shown in table 3 [8-13]. Table 3 depicts the comparison of results of the present study with the results of previous studies. When the results were compared it was observed that in all the studies the sphenoparietal type of pterion was the most frequently observed type. The frequency of other types such as frontotemporal, stellate and epipteric varied in different studies. The sutural morphology needs to be understood prior to drilling a burr hole in pterionic keyhole surgeries or while performing a pterional Craniotomy to access and operate on structures that lie beneath it such as the insula, Broca's area, optic nerve and circle of Willis vessels [1]. The sutural morphology is especially significant in case of epipteric variety when a sutural bone present at the site of pterion can confuse the surgeon regarding the point of craniotomy [14].

Table 3: Depicts the comparison of results of the present study to the results of previous studies involving diverse ethnic groups.

\begin{tabular}{|l|l|c|c|c|c|}
\hline \multicolumn{1}{|c|}{ Authors } & Ethnic Group & $\begin{array}{c}\text { Sphenoparietal } \\
(\%)\end{array}$ & $\begin{array}{c}\text { Frontotemporal } \\
(\%)\end{array}$ & $\begin{array}{c}\text { Stellate } \\
(\%)\end{array}$ & $\begin{array}{c}\text { Epipteric } \\
(\%)\end{array}$ \\
\hline Murphy, 1956 [2] & Australian & 73.2 & 7.7 & 0.7 & 18.3 \\
\hline Saxenaet al.,2003 [8] & Indian & 87.72 & 10.01 & 5.17 & 0 \\
\hline Oguzet al., 2004 [13] & Turkish & 88 & 10 & 0 & 2 \\
\hline Ilknuret al., 2009 [12] & Anatolian & 89.2 & 3.6 & 3.6 & 3.6 \\
\hline Apinhasmit et al., 2011 [11] & Thailand & 81.2 & 1.1 & 0.4 & 17.4 \\
\hline Saheb et al., 2011 [9] & Indian & 69.25 & 17.35 & 9.7 & 3.7 \\
\hline Ukoha et al., 2013 [10] & Nigerian & 75.5 & 19.6 & \multicolumn{2}{|c|}{1.83 .6} \\
\hline Adejuwon et al., 2013 [4] & Nigerian & 86.1 & 8.3 & 5.6 & 0 \\
\hline Present study, 2015 & Indian & 81.61 & 6.63 & 3.55 & 7.63 \\
\hline
\end{tabular}

Significance of sutural morphology in neurosurgical procedures: The pterional craniotomy approach to treat vascular aneurysms of circle of Willis and other tumours in the region was popularised by Yasargil in 1967 [14]. A modified subperiosteal craniotomy approach is also described that preserves the temporalis muscle and removes the bone piece around the pterion as a flap which is then replaced with excellent cosmetic results [15]. The recent advances in surgical techniques recommend a keyhole approach that uses a very minute incision on the skin followed by surgical instrumentation that are navigated through the Sylvian fissure so as to access and treat vascular aneurysms of circle of Willis [16]. Moreover, optic meningio- mas can also be accessed and surgically treated through the pterion $[17,18]$. Several authors have suggested that the surgeon needs to be very accurate while drilling the burr hole as its position must be accurate and flawless. This is especially true in case of epipteric variety of pterion where in the surgeon may consider the anterior most point of confluence as the point of drilling and this can result in orbital penetration and injury to orbital contents with loss of vision [19].

\section{CONCLUSION}

Pterion is a very important neurosurgical landmark due to the presence of several vital structures beneath it and it provides lateral access to these structures and enables surgical treatment of clinical conditions such as vascular aneurysms of circle of Willis, tumours and meningiomas. Moreover, surgical treatment of extradural hematoma involves trephination where the burr hole is made at the pterion and the intracranial tension is relieved. The recent advances in pterionic keyhole surgeries as a treatment modality for aneurysms makes it imperative for a neurosurgeon to precisely understand the sutural morphology prior to surgery especially in cases with epipteric type.

\section{Conflicts of Interests: None}

\section{REFERENCES}

[1]. Williams PL, Bannister LH, Berry MM, Collins P, Dyson M, Dussek JE, Ferguson MWJ. The skull, In: Gray's Anatomy, 38 ${ }^{\text {th }}$ Edition, Churchill Livingstone, London,1995, pp. 583-606.

[2]. Murphy T. The pterion in the Australian aboriginal Am J PhysAnthropol 1956;14:225-44.

[3]. Moore KL, Dalley AF. Clinically oriented anatomy, 4th Edition, Lippincott Williams \& Wilkins, Baltimore, 1999, pp. 836-842.

[4]. Adejuwon SA, Olopade FE, Bolaji M. Study of the Location and Morphology of the Pterion in Adult Nigerian Skulls. ISRN Anatomy 2013; 403937, 4 pages.

[5]. Lovejoy CO, MeindI RS, Mensforth RP, Barton TJ. Multifactorial determination of skeletal age at death: a method a blind tests of its accuracy. Am J PhysAnthropol 1985;68:1-14.

[6]. Cheng WY, Lee HT, Sun MH, Shen CC. A pterion keyhole approach for the treatment of anterior circulation aneurysms. Minim Invasive Neurosurg 2006;49:257-62. 
[7]. Hyun SJ, Hong SC, Kim JS. Side selection of the pterional approach for superiorly projecting anterior communicating artery aneurysms. J ClinNeurosci 2010;17:592-6.

[8]. Saxena RC, Bilodi AKS, Mane SS, Kumar A.Study of Pterion in skulls of awadh area-in and around Lucknow .Kathmandu Univ Med J 2003;1:32-33.

[9]. Saheb HS, Mavishetter GF, Thomas ST, Prasanna LC, Muralidhar P, Magi. A study of sutural morphology of the pterion and asterion among human adult Indian skulls. Biomedical Research 2011;22:73-75.

[10]. Ukoha U, Oranusi CK, Okafor JI, Udemezue OO, Anyabolu AE, Nwamarachi TC. Anatomic study of the pterion in Nigerian dry human skulls. Niger J ClinPract 2013;16:325-8.

[11]. Apinhasmit W, Chompoopong S, Chaisuksunt V, Thiraphatthanavong,P, Phasukdee N. Anatomical Consideration of Pterion and Its Related References in Thai Dry Skulls for Pterional Surgical Approach. J Med Assoc Thai 2011;94:205-14.

[12]. Ilknur A., Mustafa K.I, Sinan B.A comparative study of variation of the pterion of human skulls from 13th and 20th century Anatolia. Int. J. Morphol 2009;27:1291-1298.

[13]. Oguz O, Sani SG, Bozkir MG, Soames RW. The pterion in Turkish male skulls. SurgRadiolAnat 2004;26:220-4.
[14]. Yaoargil MG, Krayenbühl N, Roth P, Hsu SP, Yaoargil DC. The selective amygdalohippocampectomy for intractable temporal limbic seizures. J Neurosurg 2010;112:168-85.

[15]. Kim E, Delashaw JB Jr. Osteoplastic pterional craniotomy revisited. Neurosurgery 2011;68:125-9.

[16]. Cheng WY, Lee HT, Sun MH, Shen CC. A pterion keyhole approach for the treatment of anterior circulation aneurysms. Minim Invasive Neurosurg 2006;49:257-62.

[17]. Lang J. The pterion region and its clinically important distance to the optic nerve, dimensions and shape of the recess or the temporal pole Neurochirurgia 1984;27:31-35.

[18]. Schick U, Dott U, Hassler W. Surgical management of meningiomas involving the optic nerve sheath. J Neurosurg 2004;101:951-9.

[19]. Ersoy M, Evliyaoglu C, Bozkurt MC, Konuskan B, Tekdemir I, Keskil IS.Epipteric bones in the pterion may be a surgical pitfall. Minim Invasive Neurosurg 2003;46:363-365.
How to cite this article:
Qudsia Sultana, Mohammad Hafeezulla Shariff, Venkatesh Kamatth, Ramakrishna Avadhani. A STUDY ON SUTURAL MOR- PHOLOGY OF THE PTERION IN ADULT DRY SKULL IN SOUTH IN- DIAN ETHNIC GROUP . Int J Anat Res 2017;5(3.1):4096-4099. DOI: 10.16965/ijar.2017.260 